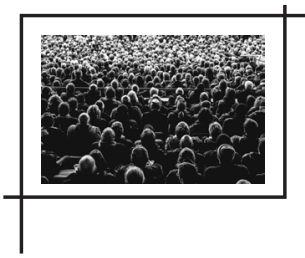

\title{
O CINEMA CONTEMPORÂNEO NA BIOPOLÍTICA: O POÇO, A CULTURA DO RALO E O LIXO SOCIAL
}

\author{
Wesley Espinosa Santana*
}

Resumo: A partir da análise da fonte filmica O poço (2019), construimos uma narrativa histórico-política do uso do corpo e das subjetividades neoliberais como produto do Estado biopolítico no Brasil a partir de 1930, no período denominado Era Vargas. A condição desse Estado biopolítico é dada a partir da função de consolidar o capitalismo industrial, incluir/excluir os trabalhadores urbanos, promover os direitos sociais e o uso da biomídia. Nesse contexto, a biopolítica produz o estado de exceção e os campos de concentração (AGAMBEN, 2014a) que, ficcionalmente, encontramos na mensagem fílmica da mediocridade humana por meio da ganância, do egoísmo e do consumo, em que a maioria vive sob a política da sobrevivência, corpo e subjetividade, garantindo as desigualdades sociais, a "cultura do ralo" e o lixo social.

Palavras-chave: Estado. Biopolítica. Era Vargas. Cinema contemporâneo. Desigualdade social.

\section{INTRODUÇÃO}

Em tempos de sindemia ${ }^{1}$ no mundo e, sobretudo, do marco de mais de 500 mil mortos no Brasil decorrentes da biopolítica em estado de exceção, o corpo e as subjetividades encontram-se, ainda mais, à mercê da política da sobrevivência, da condição de homo sacer e marginalizados dos meios de consumo e de proteção. Não longe disso, numa trajetória secular, o cinema vem traduzindo sonhos, desejos e traumas sociais e individuais, vislumbrando conquistas e derrotas, ficções e dramas baseados na vida real. Em nosso contemporâneo, a biopolítica e o cinema fundam-se no que se pode chamar de pós-verdade, pós-democracia e não corpo², e coloca-nos, como causa e efeito das relações sociais, no limbo extenuante das

\footnotetext{
* Doutor em Educação, Arte e História da Cultura pela Universidade Presbiteriana Mackenzie (UPM). Mestre em História Social pela Universidade de São Paulo (USP) E-mail: wesley.santana1@mackenzie.br

1 - Em entrevista à BBC Brasil o médico Merril Singer comenta a sua teoria sobre a sindemia a partir dessa frase criada por ele nos anos 1990 (PLITT, 2020).

2 - É a condição do não pertencimento e da antropotécnica que envolve o corpo, conduzido pelas subjetividades neoliberais e os dispositivos que padronizam a cultura e o consumo do indivíduo-individualista. 0 não corpo é tudo aquilo que não depende do indivíduo, mas que o transforma, antropotecnicamente, em outro corpo e constrói subjetividades, que Foucault (2019) denominaria dispositivos e Agamben (2014a), oikonomia.
} 
desigualdades a partir da consolidação da parceria capitalismo/neoliberalismo como solução final que traz a garantia de um caminho culturalmente natural entre vitoriosos e derrotados.

No século XX, o cinema nos trouxe, também, realização e resignação, crença e incredulidade, pacificação e luta. E, como representante dos inúmeros adjetivos que a democracia e a sociedade ganharam - sociedade do espetáculo, sociedade do cansaço, pós-democracia, democracia liberal -, foi transformado pela indústria cultural na máquina do culto ao corpo, em sua busca, em seu asco e em seu drama. Somos envolvidos por esse corpo que produz identidade, marcas, declarações, territórios, consumo e destino. Ele é a nossa apresentação, nossa prisão e nossa leitura aristotélica de bíos (vida política) transformada em zoé (vida animal). Numa sociedade em que o Estado se torna biopolítico, em que as relações desse biopoder estão postas sobre o dinheiro e entre as diferenças e a necessidade de ter, vemos a luta pela sobrevivência, ou melhor, a política da sobrevivência, que não é tanatopolítica nem necropolítica, mas, sim, biopolítica, pois a maioria ainda precisa estar viva para ser submetida ao não direito, ao não consumo, ao não corpo e, posteriormente, deixar morrer.

A biopolítica é a conduta do soberano, que tem poder sobre a vida dos súditos, mas que, com a formação do Estado liberal, permanece mostrando que não há diferença entre o que seria um governo democrático ou totalitário, mantendo uma "intima solidariedade entre democracia e totalitarismo", em que o campo - lugares como campos de concentração nacional-socialistas que transformam vidas em "vidas nuas", desprovidas de direitos e vontades - é "o primeiro paradigma do espaço político do Ocidente" (AGAMBEN, 2014a, p. 16). Segundo o filósofo Giorgio Agamben, "o século XX nos traz a concepção de uma biopolítica que se ocupa da vida dos indivíduos em sociedade não apenas como membros, patriotas ou cidadãos, mas como indivíduos coisificados e planificados pela gestão de uma doutrina liberal/neoliberal dentro da lógica capitalista" (SANTANA; SCHWARTZ, 2020, p. 79).

Essa condição de estar vivo é responsabilidade do Estado e de quem é representado por ele na exploração que garante a permanência histórica da lógica capitalista envolta nos ideais neoliberais. Por ora, a morte não é o objetivo desse Estado biopolítico, mas, sim, o controle do corpo, da representação, dos desejos e das subjetividades, visto que, fragmentados na condição do homo sacer, de marginalizados, de apolíticos e de telespectadores de sua própria tragédia, esses indivíduos se tornam naturalmente, culpados pela sua existência.

\section{A biopolítica e o Estado nacional-populista de Vargas}

Como o cinema contemporâneo pode se aproximar da biopolítica? Essa questão nos levou a um filme que se transformou em fonte filmica para o nosso estudo da biopolítica sobre o corpo, a subjetividade e a própria vida. Para isso, partimos da biopolítica dos escritos de Michel Foucault e Giorgio Agamben sobre a temática do biopoder, da sociedade do controle e do estado de exceção. Entendemos que o conceito de biopolítica e outros que orbitam ao 
seu redor são imprescindiveis para a reflexão sobre a condição humana da maioria dos indivíduos no mundo de hoje. Tendemos a aceitar que a análise histórico-sociológica da biopolítica surge a partir do momento em que a consolidação do capitalismo industrial necessitava de que mais indivíduos se tornassem consumidores, que os cidadãos fossem incluídos na sociedade com seus direitos como consumidores em escala geométrica para a garantia do empreendimento. Para Foucault (2019), a biopolítica pode ser tratada como a continuação do poder estabelecido pelo soberano, só que em vez de fazer morrer e deixar viver é o fazer viver e deixar morrer, ou seja, o soberano como dono da vida de seus súditos passaria a administrá-la e a cultivá-la. Com isso,

0 poder era, antes de tudo, nesse tipo de sociedade, direito de apreensão das coisas, do tempo, dos corpos e, finalmente, da vida; culminava com o privilégio de se apoderar da vida para suprimi-la [...]. Se o genocídio é, de fato, o sonho dos poderes modernos, não é por uma volta, atualmente, ao velho direito de matar; mas é porque o poder se situa e é exercido no nível da vida, da espécie, da raça e dos fenômenos maciços de população (FOUCAULT, 2019, p. 146, 148).

Ou seja, os indivíduos que ora estavam, limitadamente, no limbo da cidadania e do consumo foram colocados como cidadãos-consumidores para contemplar a enorme produção de mercadorias que o sistema capitalista ofereceria. Na perspectiva agambeniana, a necessidade de incluir/excluir transformou a política em política da sobrevivência, pois era necessário garantir o consumo para que se produzisse mais e concentrasse ainda mais a riqueza. Para Foucault (2008), a biopolítica ou biopoder veio com o século XVIII, com a consolidação do Estado Moderno burguês, mas, para Agamben (2014b), ela sempre existiu na história da humanidade. Em nossa interpretação, há uma diferença que não se trata de temporalidade, mas, sim, de estrutura, pois a biopolítica originou-se da consolidação do capitalismo industrial, da necessidade do consumo creditado pelos dispositivos antropotécnicos (SLOTERDIJK, 2018) que inserem os indivíduos na sociedade por meio de um padrão de corpo e de subjetividades. A biopolítica é a política da sobrevivência por meio dos corpos, desejos, escolhas e, sobretudo, do próprio consumo. Segundo Agamben (2014a, p. 122), "a grande metáfora do Leviatã, cujo corpo é formado por todos os corpos dos indivíduos, deve ser lida sob esta luz. São os corpos absolutamente matáveis dos súditos que formam o novo corpo político do Ocidente".

Olhando para o Brasil, percebemos que, a partir de 1930, com os governos de Getúlio Vargas, a política tornou-se biopolítica, e isso ocorreu, basicamente, por causa das estratégias de poder via Estado e da institucionalização do estado de exceção que tinham como fundamento consolidar o capitalismo industrial. Essas estratégias se baseiam na construção do líder populista, na criação dos direitos sociais como inclusão dos trabalhadores urbanos 
na produção, no desejo e no consumo, na centralização burocrática estatal e nas novas autarquias, no espetáculo da luta contra os opressores ao mesmo tempo que governa sob regime autoritário e impositivo, na junção da elite burguesa com a oligarquia agrária e a biomidia $^{3}$. Essas características produziram um sistema político-econômico-social-cultural que consagrou o poder como biopoder e a política como biopolítica, em que os governos varguistas incluíram os trabalhadores e controlavam-nos pelo uso do corpo, da produção, do não corpo e das subjetividades como garantia da permanência histórica da desigualdade e da exploração da maioria pela minoria. Entendemos a importância da Era Vargas para a nossa historiografia e para a própria história política, social e cultural, mas, neste artigo, teorizaremos que o período foi responsável pela formação do Estado biopolítico como instrumento de consolidação do capitalismo industrial, da inclusão dos trabalhadores urbanos, biopoliticamente controlados, inovando as relações de poder ao mesmo tempo que garantia a permanência dos quatro pecados capitais - escravismo, latifúndio, patriarcado e patrimonialismo - de José Murilo de Carvalho ${ }^{4}$ como política da sobrevivência. Carvalho (2017, p. 38-39) diz que

[...] como historiador, cabe-me perguntar por que, ao longo de quinhentos anos, houve esta persistência. 0 Brasil cresceu, não há dúvida. Somos a oitava economia do mundo. Por que crescendo dessa maneira não se alterou a desigualdade entre os brasileiros? [...] A título de explicação, diria que, olhando o problema do ponto de vista histórico, temos quatro pecados capitais que ajudam a entender a persistência. [...] A primeira delas é a escravidão. [...] 0 segundo pecado capital é o latifúndio. [...] 0 terceiro pecado capital é o patriarcalismo. [...] 0 quarto pecado é o patrimonialismo, isto é, a relação entre a sociedade e o Estado em que o bem público é apropriado privadamente.

Por esse caminho, arriscamo-nos a buscar no cinema uma relação que se aproximasse dessa nossa perspectiva de reflexão sobre o Estado biopolítico brasileiro e da condição real de milhões de brasileiros. Escolhemos uma ficção científica produzida na Espanha para exemplificar o contexto - como fonte histórica e sociológica - da produção no século XX dos

3 - Termo cunhado para explicar a formação da mídia brasileira ligada diretamente aos interesses do governo desde o início da Era Vargas, de onde se formou o Estado biopolítico. A biomídia que, mesmo na crítica a um governo que se estabelece como oposição, torna-se, simultaneamente, apoiadora das classes dominantes que sempre mantêm suas bases nos poderes republicanos. Aliás, ela é membro das classes dominantes. Diante desse pacto, ora uma, ora outra, a biomidia dita o uso do corpo e a forma de viver da sociedade por causa do espetáculo e da inconsciência anestésica social e político-cultural. A biomídia é instrumento do poder e da permanência dos privilégios, em que a maioria, sob o jugo do controle, da informação e da tendência de corpos e mentes, vive em sua vida nua, desprovida de direitos, como afirmaria o filósofo italiano Giorgio Agamben.

4 - 0 historiador José Murilo de Carvalho descreve a ideia de que há quatro pecados capitais na formação histórica de permanência incrustada em nossa sociedade que se refletem na realidade que assistimos hoje (CARVALHO, 2017). 
campos de concentração agambenianos, o estado de exceção e a vida nua como produtos da biopolítica. Segundo Agamben (2004, p. 39), "o estado de exceção não é nem exterior nem interior ao ordenamento jurídico e o problema de sua definição diz respeito a um patamar, ou a uma zona de indiferença, em que dentro e fora não se excluem, mas se indeterminam".

Nessa película, traduzida em português pelo título de 0 poço $0^{5}$ trataremos da reflexão crítica sobre o biopoder e a capacidade humana de banalizar a ganância, o egoísmo e a própria desumanidade como condição humana de indivíduos sobreviventes de um sistema desigual, violento, cruel e distópico, embasado pela realidade de excrescências e injustiças do mundo.

\section{O POÇO COMO O CAMPO DE CONCENTRAÇÃO AGAMBENIANO}

Em 0 poço ou o Centro vertical de autogestão, analisamos não apenas a metáfora do Estado e das classes sociais, mas, sim, a realidade biopolítica que mata sem querer, que promove a meritocracia e o embate pela sobrevivência de forma que o indivíduo-individualista seja a sua única garantia.

Nossa sociedade é moldada por uma construção vertical, no que diz respeito aos direitos, oportunidades, renda, escolha, consumo e destino. Em nosso país, o preto é pobre, o pobre é o neoescravo 6 e o neoescravo é o homo sacer, constituido/destituido. Na roda logística do lucro e do consumo, vemos que ter mais do que precisa não é a necessidade da sobrevivência, mas, sim, a garantia do sucesso. Nas primeiras cenas do filme ouvimos violinos - num tom requintado de aristocracia - e observamos a fiscalização detalhada do chef, um especialista dedicado ao seu trabalho com ar de sofisticação. Era o culto ao excêntrico. Era a entrada triunfal da arte do privilégio e do merecimento. Os mais de 300 andares que nos garantem essa lógica e que nos distanciam formavam, basicamente, três classes sociais - as de cima, as de baixo e as que caem - e faziam referência à sociedade dos privilégios. Ao abrir os olhos, o protagonista Goreng perguntava: "O que vamos comer?" 0 nivel era o 48. Trimagasi, seu experiente interlocutor, disse: "É óbvio! Vamos comer o que sobrar do andar de cima, o nível 47". Goreng, que buscava um certificado homologado, aprendeu a primeira lição com Trimagasi, o objetivo ali era comer para se manter vivo. Óbvio! A luz vermelha e a luz verde representavam a saída e a chegada da plataforma, uma espécie de elevador que trazia a comida

\footnotetext{
5 - The platform (titulo original).

6 - 0 neoescravo é o trabalhador manual ou subempregado, uberizado e sem direitos que cresce nas metrópoles mundiais. Suas subjetividades neoliberais os tornam a-histórico, apolítico, individualista, pseudoempreendedor e uberizado, e descrente do coletivo e da solidariedade. 0 neoescravo trabalha oito, dez, 12 ou 14 horas, dependente do serviço público em sua sobrevivência e com acesso reduzido à informação, ou melhor, com acesso ao que predomina na biomídia como suporte da sociedade dos privilégios.
} 
para ser consumida. Havia o controle do consumo pelo tempo. Os de cima abocanhavam banquetes, direitos, prazeres deslumbrantes, rituais pantagruélicos. A comida não era escassa, era suficiente para todos, mas a biopolítica produzia o desperdício com o intuito de cultivar a "cultura do ralo"7, que fazia da vida a humilhação e a luta pela sobrevivência dos individuos nos níveis abaixo. As sobras do banquete que começava sob uma plataforma no nivel zero eram a sobrevivência dos mais fortes nos outros niveis.

No prédio, onde a plataforma sobe e desce, presenciamos os limites civilizatórios. Indivíduos que chegavam por culpa ou por necessidade e escolhiam um objeto que os acompanharia no período em que ficassem no poço. Trimagasi havia levado a Samurái-Plus, que quanto mais usava, mais afiada ficava. Seu passaporte para o poço foi o homicídio culposo de um imigrante. Já Goreng levou um livro, o clássico El ingenioso hidalgo Dom Quixote de La Mancha. Uma esperança para quem queria parar de fumar e conseguir um certificado. No poço, os de cima também não suportavam a pressão e, com frequência, os corpos despencavam, enquanto os de baixo iam perdendo a coragem e resignavam-se. Paradoxalmente, ambos lutavam contra si e contra os outros. Em determinado momento apareceu Miharu, vinda pela plataforma que, antropofagicamente, sobrevivia à procura da filha. Sob o efeito do gás, eles trocavam de nível! Goreng era um comunista e Trimagasi, um resignado. No nível 171 veio o desespero e Goreng tornou-se vítima de Trimagasi. A amizade transformara-se em crime ou sobrevivência. A plataforma chegava praticamente vazia, apenas com o resto, como se fosse o ralo. Goreng seria devorado como o caramujo, por partes, numa transformação kafkiana, de tempo em tempo, de pedaço em pedaço. Não havia escolha, apenas a sobrevivência de um deles pelo consumo da carne do outro. A parte da carne comida não afetava a vida, apenas dificultava, biopoliticamente, a sobrevivência. Era doloroso, mas não fatal. Miharu consegue salvá-lo e Goreng torna-se um assassino e, também, comedor de carne humana. Comer ou ser comido? Trimagasi, se estivesse vivo, diria: "É óbvio!". A guerra híbrida sob a égide do império, do Estado biopolítico, da administração da plataforma. $\mathrm{Na}$ realidade do filme, havia uma regra no poço: os de cima não falam com os de baixo. Miharu não se limitava aos niveis e comungava das dores de cada um deles, lutando pela vida e pelo direito de sonhar com a filha. De forma sanguinária, mas não menos humana, a lógica da disputa gerava proporções ficcionais e incongruentes que não perdiam para os destinos de refugiados, marginalizados e indesejáveis no mundo real. Tortura, morte e consumo são

\footnotetext{
7 - Desenvolvemos esse conceito para discutir a formação biopolítica do cidadão-consumidor a partir da formação do Estado biopolítico. A ampliação desse cidadão se deu na intenção de consolidar o capitalismo industrial pelo aumento da produção e do consumo. Diante disso, o aumento trouxe, também, maior desperdício e maior desigualdade, produzindo a "cultura do ralo", que não se destina apenas à mercadoria como objeto, mas também ao dinheiro como sagrado e, sobretudo, o ser humano reificado em mercadoria. Na "cultura do ralo" vemos o que escoa como indesejável no mundo da lógica capitalista, pois o que passa pelo ralo torna-se o lixo social.
} 
armas que esses individuos, sob o controle do corpo, usavam para sobreviver. A carne de Trimagasi estava agora na digestão de Goreng e ambos formavam um só corpo. 0 companheiro morto tornou-se um daimon. Goreng não queria aceitar a luta desigual da acumulação de privilégios como regra. Imoguiri, a nova companheira de Goreng no nível 33 e voluntária na plataforma, definia que havia 200 andares e que o poço era, na verdade, o lugar em que se ensinava a solidariedade espontânea. Ela dizia a ele: "Haveria comida para todos se comessem só o que precisassem". Ela trabalhou na administração do poço por 25 anos e, agora dependente da plataforma, com câncer terminal, tinha o cuidado pedagógico de preparar as refeições para os níveis de baixo, com a ideia de racionar a comida para que chegasse a todos, mas ninguém aceitava. "O poço não é um bom lugar para quem gosta de ler", disse ela a Goreng. Banalmente, ela levou muitos ao poço sem saber o que acontecia lá. No topo do nível zero o banquete estava montado. Havia fome e desperdício sarcásticos. Após outro gás, chegaram ao nível 202. Goreng comia a carne da recém-enforcada companheira solidária e arrependida. Nas paradas seguintes da plataforma, apenas objetos quebrados. Goreng comia páginas heroicas de Dom Quixote. Ele sobreviveu comendo orelhas, papadas e seios de sua segunda companheira. Com o cheiro do gás, ele chegou ao nível 6. Goreng se uniu a Baharat e formulou um plano: descer pela plataforma armado de barras de ferro até o último nível, racionando a comida a partir do nível 51 até o final. Tinham que descer tudo e proteger a comida e a panna cotta para provar que era possivel a comida para todos. Era a Revolução pelo Consumo. Outro sobrevivente - um sábio em cadeira de rodas - dizia que "a administração não tinha consciência e que quando a panna cotta fosse até o final do poço e voltasse para o nível zero, a lógica estaria quebrada". A partir do nível 51, eles começaram a dividir os pratos, mas a plataforma só parava no nivel em que havia pessoas vivas. Um velho que fazia uma chuva de notas de dinheiro se apresentava inerte e improdutivo diante da fome. Conseguiram ir até o final com a panna cotta que foi definida como símbolo da resistência, como a mensagem. Feridos chegaram ao nível 333. Viram uma menina. Ilusão ou esperança? Deram-Ihe a panna cotta, que logo devorou. Com a morte de Baharat, Goreng e a menina continuaram a descer e chegaram ao último nivel. Goreng saiu da plataforma e, conversando com o seu daimon, concluiu que a jornada havia terminado e que ela, a menina, era, na realidade, a mensagem que, incólume, subia sozinha pela plataforma. Goreng sobreviveu, pois acreditava que era possível reverter o sistema e mudar as regras.

\section{O RALO COMO BIOPOLITICA DO HOMO SACER OU DOS INDESEJÁVEIS E MARGINALIZADOS}

Goreng chegou ao fim do poço e, ferido, estava livre. Na "cultura do ralo", ele escapou da saída dos indesejáveis e dos não consumíveis, que morriam ou sobreviviam. Governos, trans- 
nacionais, Forças Armadas, capitalismo financeiro, império, latifúndio, neoliberalismo e intolerância cercam os diferentes, separando-os por níveis, entre fartura e escassez, ganância e sobrevivência, os que devem consumir e os que devem, resignadamente, sobreviver em condições subumanas. Esses indivíduos que sobreviviam no poço não eram vítimas da essência hobbesiana, mas sim do Estado biopolítico inoperoso, em que a potência não é o ato ${ }^{8}$, em que o Estado não é mais o administrador de suas vidas, mas sim a não potência diante de todas as antropotécnicas e dispositivos das subjetividades neoliberais, dos cultos ao corpo e ao espetáculo e da biomídia como produtores da biopolítica. São estigmatizados pela segregação da cor, da origem e do território, entre o trabalho intelectual e o manual, entre força e fraqueza, sucesso e fracasso. Aos que estão no fim do poço, saindo pelo ralo, numa sociedade desigual, espetacular, biomidiática e de biopolítica dos campos de concentração, vemos que a menina sã e salva se torna a utopia maior sobre a luta e o futuro dos que não se entregam à lógica. Segundo Bazzicalupo (2017), a biopolítica transforma a ordenação do direito, o modelo jurídico-repressivo é substituído pela aclamação, pelos apelos direcionados ao povo, trazendo a justiça para o senso comum com a capacidade de produção de subjetividades.

Escolhas e decisões políticas são cada vez menos justificadas no quadro do direito, preferindo optar por apelos diretos ao sentimento público que é posto diante de alternativas apaixonadas que envolvem vida e morte, bem-estar ou pobreza [...]. Contribuem para tal simplificação tanto a desrealização midiática da experiência - que busca uma compensação através de imagens fortes, sanguíneas e alternativas secas, que se resumem a frases de efeito - como a paradoxal e ambivalente centralidade do corpo, o último estágio do processo moderno de individualização, mas também limiar daquilo que ainda nos agrega (BAZZICALUPO, 2017, p. 20-21).

Como é determinada a hierarquia do poço? Na primeira leitura, a mudança parece aleatória, mas logo percebemos que se trata de um sorteio didático, buscando a solidariedade espontânea que, biopoliticamente, expressa o pior do humano, a intolerância e a indiferença. 0 poço é inoperoso como o Estado, pois ele é potência, mas não é ato, e isso nos mostra que a sua ausência é responsável pela produção das biopolíticas. 0 reflexo dessa metáfora e dessa construção ficcional é a base da nossa sociedade contemporânea sob a lógica do capital, sob a ganância e a inversão de valores nos quatro pecados capitais de José Murilo de Carvalho. A formação do Estado biopolítico brasileiro foi o projeto de permanência dos pecados capitais pelo ciclo político-cultural do que chamamos de a teoria das três etapas do

8 - "Quando Aristóteles enfatiza que todas as coisas têm ato (enérgeia) e potência (dýnamis), determina, ao mesmo tempo, que a potência pode não passar ao ato e, por isso, tornar-se impotência ou não potência (adýnamis), mas isso não significa a sua inexistência, e sim o voltar-se da potência a si mesma para doar-se a si mesma" (AGAMBEN, 2014a, p. 52). 
processo de fracassos: família, escola e trabalho ${ }^{9}$, que mostra que aquilo que a sociedade produz é, culturalmente, vertical, como a plataforma e o poço no destino da maioria, viável e compreensível diante da lógica do capitalismo neoliberal, que oferece fartura aos de cima e escassez aos de baixo. No Brasil varguista, um exemplo da biopolítica pode ser visto em trabalhadores que eram considerados cidadãos. Esses eram os trabalhadores urbanos, protegidos pelas leis trabalhistas do governo, que "estariam associados à industrialização, à modernização, à máquina, ao enriquecimento do Brasil [...]. Por outro lado, os rurais ficariam ligados à tradição, à nacionalidade e à produção para o consumo nacional e internacional" (LAG0, 2017, p. 31).

A biopolítica, como ato sobre o corpo e o não corpo, é a função permanente dos fracassos na família e, por consequência, na escola e no trabalho. É o fracasso da desigualdade e da falta de oportunidade. A teoria das três etapas do processo de fracassos se justifica na péssima condição das moradias, na migração involuntária para as metrópoles, na saída para a periferia como "cultura do ralo", na falta de infraestrutura, nas reformas educacionais, no sucateamento das escolas públicas, na falta de empregos e nos desempregados e desalentados. Buscar uma vida melhor, com saúde, paz e felicidade é um paradoxo para estes indivíduos que estão atrelados ao ciclo de fracassos, permanentemente, destinados a descer aos niveis mais baixos da sobrevivência. Em suas subjetividades neoliberais, o indivíduo torna-se atomizado, um indivíduo-individualista em sua condição ontogenética e filogenética que é livre para receber, sozinho, a culpa pelo fracasso. Ele não se compara a ninguém pelo que é, mas sim pelo que não tem e pelo que se imagina ser.

A plataforma que guia a sociedade contemporânea é a lógica do capital, do desejo e do consumo, esquivando-se da solidariedade e da alteridade. A distribuição desigual, o papel fracassado do Estado dentro das perspectivas sociais e a derrocada das representações políticas no mundo sustentam a plataforma, garantindo que os niveis se tornem permanentes e que a pouca energia que resta seja usada para a sobrevivência. Há um tempo, há um intervalo em que a plataforma age, tentando nos trazer uma sensação democrática, justificando que todos têm o mesmo tempo de consumo, o mesmo tempo de desejo e de felicidade. Dentro da plataforma como lógica do capital, de onde não encontramos ainda uma saída para uma democracia social, traduzimos em teoria sua função de fazer essa distribuição aparente do consumo como condição única e natural do caminho que as sociedades tomaram no ciclo permanente de fracassos.

9 - 0 conceito define-se por um projeto das classes dominantes para garantir a permanência do ciclo vicioso de desenvolvimento socioeconômico-politico-cultural das camadas pobres da sociedade mediante o elo de sucessivos fracassos na familia, na escola e no trabalho. Esses fracassos geram a autoculpa, o determinismo e a naturalidade em aceitar um corpo e uma vida sem direitos e sem felicidade. Acreditamos que esse ciclo de fracassos se formou na origem do Estado biopolítico sob a condição de incluir/excluir, sobretudo, pobres, pretos e braçais do certame político, ou seja, da pólis como o lugar da política. 
Vemos em nosso país a quantidade de comunidades e de moradias sem esgoto e sem água potável. Casas de madeira reutilizadas, moradias em morros e pontos de perigo constante de desabamento. Com a superpopulação concentrada nas grandes metrópoles por causa da desigualdade de oportunidades de trabalho, desarticula-se a possibilidade de se criarem políticas públicas que beneficiem a maioria da população. Nessas moradias, a principal instituição em ruína não é sua estrutura ou localização, mas sim suas famílias vivendo na escassez, no ambiente da violência e do controle do Estado paralelo, que garante o assistencialismo como moeda do silêncio e cooperação. Pais ausentes, neoescravos em subempregos ou desalentados que buscam no tráfico e no poder paralelo a condição da sobrevivência e a luta contra o Estado e as classes dominantes, milhões de crianças já nascem em famílias com essa realidade fracassada e, com poucas exceções, a maioria manterá a engrenagem do controle do corpo sob as subjetividades neoliberais que chegam à escola e, depois, cada vez mais dificil, ao emprego formal ou ao trabalho.

Se olharmos para as nossas escolas públicas da periferia de grandes cidades como São Paulo, perceberemos que a maior parte dos discentes é parda ou preta, e que pouquíssimos têm apoio de pais ou familiares ou mesmo condições de continuar os estudos no contraturno das aulas. Os prédios são trancafiados com grades, cadeados e barras de ferro. Em geral, as janelas estão quebradas e sem cortinas. As refeições se tornam um atrativo na política da sobrevivência. Eles têm o que merecem? Por mais interesse que a comunidade tenha para retirar a ideia de que é merecedora do descaso e do destino, o tempo e o espaço a movem para a realidade cruel da ignorância e da desigualdade. A utopia existe quando se percebe que é na escola que se faz a última refeição do dia, se não a única. Receber o material escolar, em que o livro didático - dado como mercadoria de enorme lucro - é a única referência material do programa governamental e a bandeira de uma educação para todos em niveis diferentes na manutenção da sociedade dos privilégios. A parceria público-privada, raiz das relações patrimonialistas, tem nessas escolas uma renda garantida. Dentro da sala de aula, os alunos interessados e com entendimento sobre a importância da escola devido à sua história e às experiências familiares percebem que sonhar e buscar uma condição melhor de vida é uma luta desigual. A vida pobre, difícil, da casa para a escola, de fracasso em fracasso, de poucos sonhos e muitas desilusões deixam marcas que, para eles, fazem do lugar que vivem o não lugar, modificados pelo não corpo sob a égide do controle e da biopolítica.

A luta é incessante, pois a venda de drogas está na lógica do capital, dentro da escola, nas subjetividades construidas pela busca do prazer, do alívio e da comparação no que eles veem pela biomídia. A "escola de graça", como muitos dizem, é uma escola que presta? Ser de graça é sinônimo de ruim? Vivemos nos niveis da abundância e da escassez, da resignação e da resiliência, em que a plataforma chega, mas não modifica a realidade vivida. Essa escola pública foi arregimentada como dispositivo de controle e permanência das indiferenças. A escola pública tornou-se escola para pobre e preto, a biopolítica. Assim, a pobreza que, em 
todos os aspectos, sustenta a riqueza, é, também, o que a promove como espetáculo das subjetividades neoliberais.

Completando esse ciclo, essa roda do desenvolvimento tecnológico-econômico-neoliberal, temos o trabalho, o subemprego, o trabalho braçal, o neoescravo, motoristas, pedreiros e empregadas domésticas. 0 pobre infeliz deseja ser o trabalhador constituído pelo imaginário social, da apropriação do senso comum trazida pelas biomídias e as biopolíticas educacionais que definem o sucesso como a concorrência de todos contra todos, dentro da lógica do capital da produção e do consumo.

0 poço, a "cultura do ralo" e o lixo social são a condição permanente dos pecados capitais e da nova forma de relação de poder pela biopolítica. 0 poço nos mostra a natural desigualdade, o ralo elimina o indesejado que se torna o lixo social. A comida que é a mercadoria e que é o sustento se torna, territorialmente, a moeda de troca na política da sobrevivência. E negociar com fome e fracassos já nos mostra quanto esse sorteio didático da presença nos níveis é desigual e tão perto da realidade que vivemos em nosso país e no mundo.

A teoria das três etapas do processo de fracassos: familia, escola e trabalho é, justamente, a reificação do indivíduo como mercadoria (MARX, 2017). É o resultado da formação do Estado biopolítico, que, na potência, apoia, ininterruptamente, todas as classes sociais, mas, no ato, garante a versão das classes dominantes e de sua ideologia hegemônica. Nela, visibiliza-se o estado de exceção. A escola ou a educação que, por muitos, é dita como a saída às questões sociais no Brasil, tornou-se, paradoxalmente, a justificativa capitalista neoliberal do processo de fracassos pela competição entre diferentes e desiguais, ricos e pobres, brancos e pretos, homens e mulheres.

\section{CONSIDERAÇÕES FINAIS}

Ao percebermos que para Goreng a saída para a condição de política da sobrevivência seria pela Revolução pelo Consumo, nossa leitura permitiu pensarmos que as rupturas politicas e econômicas deverão surgir de baixo para cima, da maioria contra a minoria, partindo de pequenos territórios, de administrações comunitárias e coletivas, de bancos locais, de educação social, e que os grupos politizados devem se conscientizar da importância da força da maioria que, na lógica do capital, está no consumo, fomentando a política e a economia para si, pela construção de uma democracia social: igualdade de oportunidades, sustentabilidade e desarticulação dos quatro pecados capitais. 0 Estado biopolítico é a potência e é criado para a permanência histórica da desigualdade, garantida pelo controle do desejo e do consumo dado pela lógica capitalista. Decorrente disso, o uso da biopolítica é o ato como versão, pós-verdade e destino. A morte ainda é subproduto da biopolítica e, por isso, como política da sobrevivência, dá-nos outra saída, que é a luta contra as subjetividades neolibe- 
rais, que justificam a "cultura do ralo" como solução eugênica e o lixo social como mérito. Para Goreng, a leitura foi ferramenta e a não resignação foi estratégia para a saída do poço. 0 que, para nós, também o são. E isso é óbvio.

\title{
Contemporary cinema in biopolitics: the well, the culture of the drain and social waste
}

\begin{abstract}
Based on the analysis of the source film 0 poço (2019), we built a historical-political narrative of the use of the body and subjectivities to illustrate the formation of the biopolitical state in Brazil in the mid-1930s, in the period known as the Vargas Era. The condition of this biopolitical State is given from the function of consolidating industrial capitalism, including/excluding urban workers, promoting social rights and the use of biomedia. In this context, biopolitics produces the state of exception and concentration camps (AGAMBEN, 2014a) that, fictionally, we find in the filmic message of human mediocrity through greed, selfishness and consumption, in which most live under the politics of survival, body and subjectivity, guaranteeing social inequalities, the culture of the drain and social waste.
\end{abstract}

Keywords: State. Biopolitics. Vargas Era. Contemporary cinema. Social inequality.

\section{REFERÊNCIAS}

AGAMBEN, G. Estado de exceção: homo sacer, II, I. Tradução Iraci D. Poleti. 2. ed. São Paulo: Boitempo Editorial, 2004.

AGAMBEN, G. Homo sacer: o poder soberano e a vida nua I. Tradução Henrique Burigo. 2. ed. Belo Horizonte: Editora UFMG, 2014a.

AGAnBEM. G. O amigo \&t o que é um dispositivo? Tradução Vinícius Nicastro Honesko. Chapecó, SC: Argos, 20146.

BAZZICALUPO, L. Biopolítica: um mapa conceitual. Tradução Luisa Rabolini. São Leopoldo: Editora Unisinos, 2017. (Coleção Aldus, 44).

CARVALHO, J. M. de. O pecado original da república: debates, personagens e eventos para compreender o Brasil. Rio de Janeiro: Bazar do Tempo, 2017.

FOUCAULT, M. O nascimento da biopolítica. Tradução Eduardo Brandão. São Paulo: Martins Fontes, 2008.

FOUCAULT, M. História da sexualidade: o cuidado de si. Tradução Maria Thereza da Costa Albuquerque e J. A. Guilhon Albuquerque. 6. ed. São Paulo: Paz e Terra, 2019. v. 3. 
LAGO, M. C. Trabalhadores do Brasil: uma reinvenção dos imaginários sociais sobre os trabaIhadores no varguismo. In: MOURELLE, T.; FRAGA, A. (org.). Olhares sobre o governo Vargas. Rio de Janeiro: Autografia, 2017. p. 14-46.

MARX, K. O capital: crítica da economia política. Livro III: o processo global da produção capitalista. Tradução Rubens Enderle. São Paulo: Boitempo Editorial, 2017.

0 POÇO. Direção: Galder Gaztelu-Urritia. Intérpretes: Ivan Massagué, Zorion Eguileor, Antonia San Juan et at. Espanha: Netflix, 2019. (1h34min), streaming.

PLITT, L. 'Covid-19 não é pandemia, mas sindemia': o que essa perspectiva científica muda no tratamento. BBC.com, 2020. Disponivel em: https://www.bbc.com/portuguese/internacional-54493785. Acesso em: 10 out. 2021.

SANTANA, W. E.; SCHWARTZ, R. M. P. B. As mulheres nos anos 1930 e a luta por direitos no Brasil. In: SCHWARTZ, R. M. P. B.; ABIORAMA, D. N. (org.). Território feminino. São Paulo: Editora e-Manuscrito, 2020. p. 77-88.

SLOTERDIJK, P. Tens de mudar de vida. Lisboa: Relógio D'água, 2018. (Coleção Antropos). 